\title{
A proposed water sector plan for the Dr Kenneth Kaunda District Municipality (Dr KKDM)
}

\author{
M. DIEDERICKS AND EJ NEALER ${ }^{2}$
}

\begin{abstract}
The radical reform of potable water services provisioning by means of promulgation of the Water Services Act 108 of 1997 and the National Water Act 36 of 1998 in South Africa (SA) started a process of addressing the imbalance which existed in how the national resource was distributed. Water is now recognised as a scarce resource that belongs to all the people of the country and consequently it should be managed in an integrated way for social and economic development including future growth (Fuggle and Rabie 2005:293; Riemann, Chimboza and Fubesi 2012:446). The provision of potable water by water services authorities (WSAs) is an important basic service that faces a number of challenges such as the use of out-dated infrastructure and a lack of skilled and knowledgeable people that place overt pressure on demand for service delivery. It is against this background that the researchers have undertaken to investigate how a municipality which is forced to obtain its potable water supply from nearby surface- and groundwater catchments, can manage it in a more effective, efficient, equal, economic and sustainable manner by means of improved planning procedures to enhance co-operative governance and intergovernmental relations.
\end{abstract}

A qualitative research design was used to conduct the study, which included a literature review, semi-structured interviews, non-probability data sampling and scientific analyses of responses. Furthermore, a case-study approach was followed by the researchers, with Dr Kenneth Kaunda District Municipality (Dr KKDM) as the unit of analysis (the locus). The major research finding of the study included that a Water Sector Plan (WSP) was lacking and non-existent in the Dr Kenneth Kaunda District Municipality (Dr $\mathrm{KKDM}$ ) and therefore water services delivery could not be coordinated effectively.

Keywords: water, environment, water resource management, planning, coordination, public participation, integrated development plan, strategy, water services development plan, legislation, regulation.

\section{Introduction}

The supply of potable water and basic sanitation services to all inhabitants of South Africa (SA) has never been higher on the national, provincial - and especially on the local government spheres' agendas - than at the end of April 1994. At that time thirty-five percent of South Africans had no access to a basic water supply, and fifty-three percent lived without proper sanitation (Funke, Nortje, Findlater, Burns, Turton, Weaver and Hattingh 2007:12). As a result of the change in government, all the executive public institutions on all three spheres had to revisit and transform their executive authorities, acts, regulations and work procedures, in such a manner, that a more equitable benefit for all the citizens of the country could be achieved (Nealer and Raga 2008:295).

Dr M Diedericks, School of Social and Government Studies, Public Management and Governance, Prof EJ Nealer, Public Administration and Management, University of South Africa, Pretoria.

TD The Journal for Transdisciplinary Research in Southern Africa, 11(1) July 2015, pp. 64-81. 
With reference to national water affairs, the Water Services Act 108 of 1997 and the National Water Act 36 of 1998 were promulgated, in order to provide for the necessary reform (improved equity, sustainability, efficiency and integrated water resources management) of the law relating to water resources in SA. For the first time, potable water was now recognised as a scarce and unevenly distributed national resource that belongs to all the people of the country, and that the water collected in the various rainfall catchment areas (river basins and underground cavities, channels and fractures) and water resources be managed in a more integrated way (Fuggle and Rabie 2005:293).

The key role-player in managing water resources in this sector is the current Department of Water Affairs and Sanitation (DWS). This study was completed in 2012 when the DWS still went by the name of the Department of Water Affairs (DWA) and before the new National Water Resource Strategy (NWRS) came into effect. Reference is therefore still made in this article to the DWA and the NWRS 2004. The DWA is responsible for ensuring that water is protected, used, developed, conserved, managed and controlled in a sustainable and equitable manner (NWP 2006:18).

On the local government sphere of the developing SA, the effective, efficient, equal, economical and sustainable municipal management of potable water supply also entails the execution of highly complex hydrological, geo-hydrological and public management functions in a dynamic and highly regulated environment. It inter alia, entails the conservation of suitable water resources - by firstly: identifying, surveying, and the demarcation thereof, and then the development, transport, treatment, distribution, imposition of tariffs, municipal administration, re-collection of the used water, treatment and final release of the wastewater back into the water catchment for use by other downstream users (Nealer and Raga 2008:295). In addition, the nature and impacts of the physical environment are also difficult to manage. It now, therefore, requires the municipal managers and leading officials, as well as the committed political office-bearers - in addition to their normal municipal management knowledge and functions - to be equipped with some basic knowledge and information regarding the physical environment (the hydro-geological aspects of water resources), and to utilise the necessary geographical mapping tools, in order to improve their long-term planning and service delivery skills (Nealer and Raga 2008:295).

\section{Locus and problem statement of research}

This research concentrated on the place and role of the Dr Kenneth Kaunda District Municipality (Dr KKDM) with its incorporated four Category B Local municipalities, namely the Maquassi Hills Local Municipality (MHLM), the Matlosana Local Municipality, (a.k.a. City of Matlosana), the Tlokwe Local Municipality (a.k.a. Tlokwe City Council) and the Ventersdorp Local Municipality. (See 1Figure 1 below for some topocadastral information on the locality of the municipalities).

The Strategic Framework for Water Services of 2003 (DWAF 2003:42) outlines that if a district municipality is not a WSA, it is not required to develop a Water Services Development Plan (WSDP). The district municipality should, however, develop a "water sector plan" addressing the district-wide issues arising from the local WSDPs, and include this in the district's integrated development plan (IDP). The current practices of potable water supply management by Dr KKDM in its municipal area were investigated according to the availability or lack of a District Water Sector Plan (DWSP). The key motivation was thus to develop a plan or functional flow chart that would outline the roles and responsibilities of

Td 11(1), July 2015, pp. 64-81. 
all role-players involved to manage water resources more effectively on strategic, tactical and operational levels within government structures and to assist in realising integrated water resources management (IWRM).

Figure 1: Locality map of the Dr Kenneth Kaunda District municipal area

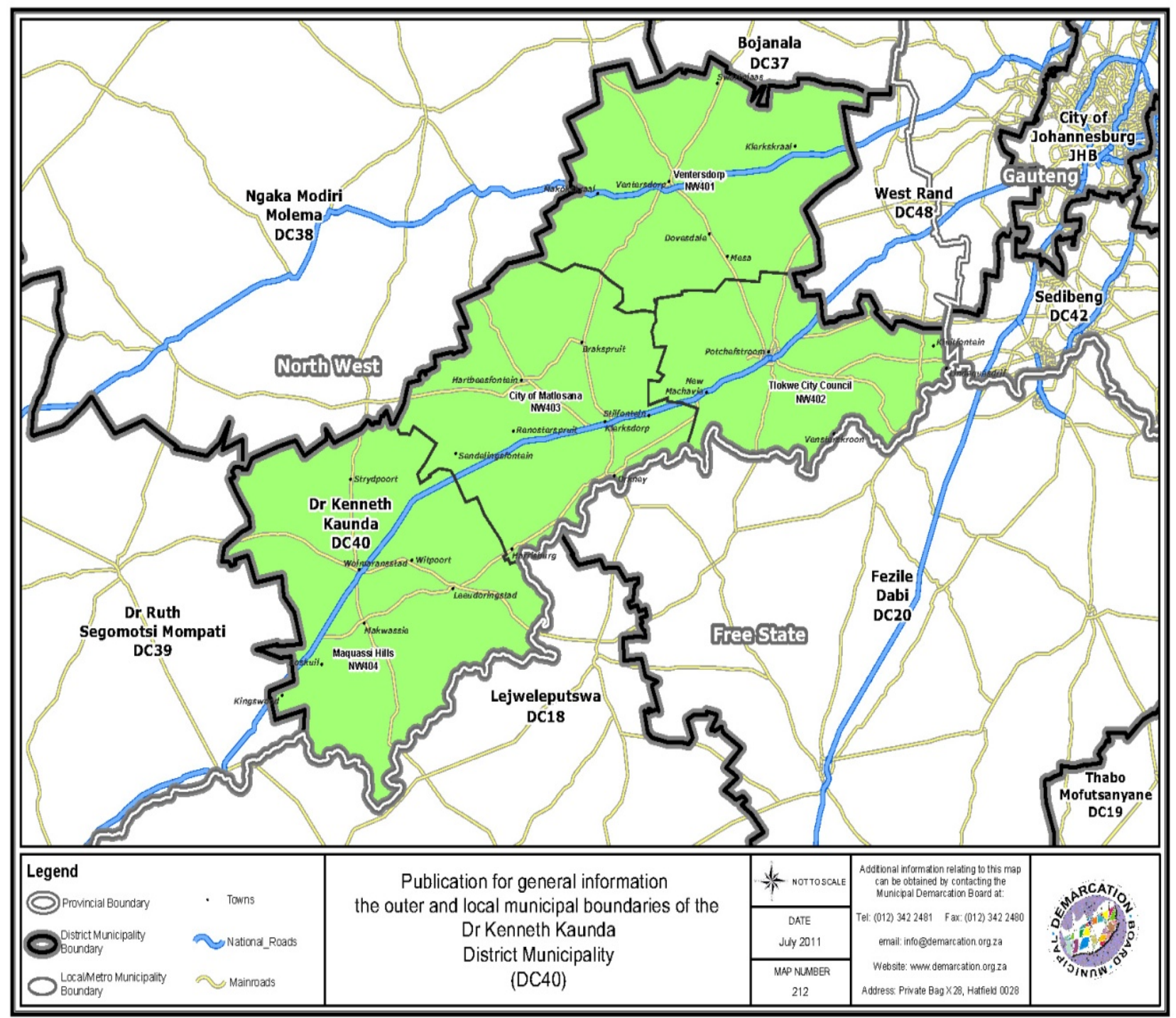

Source: Demarcation Board 2011.

\section{Research objectives}

The primary objective of the study was to determine how a municipality which has to obtain its potable water supply from a nearby surface-and groundwater catchment(s) can manage it in a more effective, efficient, equitable, economic and sustainable manner by following a proposed district water sector plan, illustrated by means of a functional flow chart.

To achieve the afore-mentioned primary objective, the following secondary research objectives were explored:

- To investigate and analyse the nature and extent of potable water supply management and to apply criteria that could contribute in assessing and improving water-related planning by a district municipality in its municipal area of jurisdiction. 
- To investigate and analyse compliance with the legislation, regulations and strategies of municipal water resources management, in order to identify strategically important aspects to be taken into consideration by municipalities (WSAs), Water Services Providers (WSPs) and Water User Associations (WUAs) which have to obtain their potable water from nearby surface- and groundwater catchments.

\section{Legal framework and policies}

As mentioned, the 1994 election of a new government in SA gave rise to a remarkable transformation process in the water services sector. Section 27 of Constitution of the Republic of South Africa, 1996 addresses the right of access to sufficient water. The transformation of water services in SA has mainly been influenced by the implementation of new legislation and a regulatory framework, including water-related strategies. Transformative water-related legislation includes the White Paper on a National Water Policy, 1997, the Water Services Act 108 of 1997 and the National Water Act 36 of 1998. The promulgation and implementation of these Acts were to assist the processes of redressing the inequalities of racial and gender discrimination of the past; to link water management to economic development and poverty eradication; and to ensure the preservation of the ecological resource-base for future generations. The National Water Resource Strategy 2004, which includes Water Catchment Agencies (CMAs) and Water Users' Associations (WUAs) have contributed towards meeting the basic needs of present and future generations; to promoting equitable access to water, including the efficient, sustainable and beneficial use of water in the public interest. The aforementioned legislative framework and related water strategies lay the foundation for potable water supply management within SA, but more specifically on the local government sphere where potable water is regulated by the Local Government: Municipal Structures Act 117 of 1998 and the Local Government: Municipal Systems Act 32 of 2000. The Local Government: Municipal Structures Act 117 of 1998 defines the different types of municipalities; it establishes the necessary criteria, and makes provision for the division of powers and functions between the different categories of municipalities. The Act furthermore determines whether a municipality is a WSA or not that would be responsible for the provisioning of potable water supply. The Local Government: Municipal Systems Act 32 of 2000 distinguishes between the functions of a WSA and water services provider. According to the said Act, services can either be provided by the municipality or appointment of external service providers (e.g. in the Maquassi Local Municipality, also located in the Dr KKDM, potable water services is provided by a water company namely Sedibeng Water).

In the next section, arguments for more effective water services planning are subsequently discussed.

\section{Planning for more effective potable water services delivery}

As secondary research objective of this study, it investigated and analysed the effective functioning of planning within South African governance structures as part of the interrelated system of intergovernmental relations and co-operative governance as tools to improve basic service delivery, such as potable water supply management - by involving all the relevant roleplayers and stakeholders in the public decision-making processes.

In terms of planning for water each sphere of government fulfils an important role. National Government's role in managing, protecting and determining the use of scarce water resources

Td 11(1), July 2015, pp. 64-81. 
is contained in the principle of "public trust". Public trust relates to Government not owning the water, but having the overall responsibility and authority to ensure that all the water in the country is managed for the benefit of all the citizens. This responsibility, in accordance with the NWRS (Chapter 1.2) includes ensuring that water is allocated equitably and that environmental values are promoted. National Government is committed to carrying out its public trust obligations, by being the custodian of the nation's water resources through the Department of Water Affairs (DWA). Provincial legislatures are key agents in supporting municipalities in achieving their objectives, and in ensuring that local municipalities perform effectively. Many municipalities need assistance and guidance to develop the capacity required to prioritise, plan and implement their programmes. The provinces can provide support to municipalities in a number of areas, including financial, human resources and technical skills. The aforementioned is also emphasised in the White Paper on Water Supply and Sanitation Policy (RSA 1994:10-11). Furthermore, in terms of Section 114(2)(a) and (b) of the Constitution, provinces must provide mechanisms to ensure that all provincial executive organs of State are accountable to it, and it should maintain oversight by exercising provincial executive authority in the province - including the implementation of legislation and ensuring oversight regarding any provincial organ of State. National and provincial government spheres thus facilitate important roles in the planning and management of water resources in SA. The most important functionary regarding planning for more effective water services is the local government sphere, which consists of municipalities. Municipalities providing water services are entitled Water Services Authorities (WSAs). Their responsibilities and duties according to Thompson (2006:712), inter alia include: providing access to water services; developing and implementing water services development plans; monitoring the performance of water services providers; and making by-laws.

The above duties and responsibilities are outlined in the Water Services Act 108 of 1997. The planning process at local government sphere is spearheaded by the respective integrated development plan (IDP) of each mjunicipality. It is therefore important that the WSDP, which is the planning instrument within a municipality's water services sector, must be aligned with the targets of the IDP in order to address, amongst others, the socio-economic, technical, financial, institutional and environmental issues pertaining to water services.

\section{Research design}

A qualitative research design was used to conduct this study. It involved a thorough literature review, semi-structured interviews and the distribution of a 5-point Likert-scale questionnaire with 29 statements and 4 open-ended questions, data sampling and scientific analysing of responses - including direct observations. The study made use of this qualitative method to determine the perceptions of individuals involved in the planning and management of water services within Dr KKDM. Furthermore, a case-study method/approach was utilised in this study, which involved an in-depth examination of potable water resource management by the Dr KKDM (unit of analysis) as institution, including its four incorporated and subordinate local category $\mathrm{B}$ municipalities. The evaluation involved analysing the information gathered from different sources and analyses of official documentation (Acts, water strategies, etc.), past records and audio-visual materials (such as photographs and digital voice recording of interviews). In this particular study, one of the researchers spent an extended period of time on-site to interact with the people who were being interviewed, and to determine how potable water is currently being managed. All the findings were recorded, including information on the physical environment, and 
historical, economic, and social factors that could have an influence on the situation. Triangulation was utilised as part of the case-study method which involved consulting existing legislation, guidelines and protocols regarding potable water management supply, and holding interviews with the identified role-players and stakeholders, in order to determine the current practices with regard to potable water management supply in and by municipalities of the Dr KKDM.

\section{Population and sample}

The total target population size $(\mathrm{N})$ of this study amounted to forty-two (42) respondents while the sample size (n) was thirty-five (35) respondents. The total population size comprised of eight members each from the four local municipalities, four members from the district municipality, four members from two water companies, and two independent water consultants that were previously attached to local municipalities located within the $\mathrm{Dr}$ KKDM's municipal area. All the relevant municipal councillors (entrusted with water services delivery in their portfolio) and officials employed on senior-, middle-, supervisor and technical post levels involved in potable water management were targeted and selected as respondents to form the total target population. By using this method (purposive nonprobability sampling by utilising Dr KKDM as the unit of analysis in a case-study approach), every possible person involved in managing the provision of potable water had an equal chance of being included in the sample. It is worth mentioning that the respondents involved in potable water within the Dr KKDM represented a small group equipped with specialised expertise and experience; and therefore, all the relevant respondents were targeted for participation in the study.

Non-probability sampling, according to Babbie and Mouton (2002:166-168) and Maree et al. (2012:176-178), does not make use of a random selection of population elements, but it has advantages if the population is difficult to find. Non-probability sampling is also less complicated and more economical in terms of time and financial expenses than probability samples (Welman, Kruger and Mitchell, 2011:68). All the relevant respondents were, therefore, targeted to participate in the study and eventually only 35 of the 42 respondents willingly participated.

\section{Data analysis}

All information (the literature review) and data (observations, case-study method, questionnaire and semi-structured interviews) obtained were scientifically analysed. Statistical analyses of results were described according to Frequencies and Non-parametric correlations between Likert scale statements. Qualitative data gathered were organised according to themes derived from questions in the interview schedule. Consistencies and differences in responses received from respondents were identified and grouped together. Furthermore, computer-generated graphs and tables were used to reflect the values/perceptions and technical input of the respondents. On the basis of the relevant information received, logical conclusions and recommendations were made, and a proposed water sector plan illustrated by means of a functional flow chart was developed.

\section{Strengths and limitations of study}

The limitations of the study are that the proposed water sector plan developed by means of this study is only relevant for a specific area, namely the Dr KKDM, within the local 
government sphere. This is due to the fact that a case-study approach was followed. As outlined by Babbie and Mouton (2002:166), Welman, Kruger and Mitchell (2011:193), and Maree et al. (2012:76), a case-study approach provides an in-depth study of a singular case (limited number of units of analysis) and its scientific results cannot necessarily be generalised. The results of well-selected cases, however, constitute in the social sciences a dewdrop in which the world is reflected. This implies that the case could be used to learn from and to improve possible shortcomings, where necessary.

In this regard, the significance of the water sector plan developed by means of this study has not been determined for the entire North West Province, including the rest of the South African local government sphere. Generalisations are, therefore, only limited to the locus of the study, namely, Dr KKDM's jurisdiction area. This might to a certain degree diminish the prospect of credibility of the study, although as mentioned in the previous sentence, it provides in its singularity a concentration of the global in the local.

\section{Ethical considerations}

The researchers did not manipulate the respondents (no unethical tactics or techniques were used in the interviewing process) or any of the data. The respondents were assured of confidentiality; hence, the anonymous completion of the questionnaires and participation in the recorded semi-structured interviews (with consent acquired prior to the interview). The researchers did not divulge any confidential information, and has ensured the protection of the participants' identities including the assurance not to harm the respondents in any way. The researchers also outlined to respondents the risk of participating in the study, and informed the respondents that the research was done based on generally accepted norms, standards and values of the North-West University. They were also informed that they could withdraw their participation at any point as the research unfolded.

The next section discusses the analysis and interpretation of the data collected as part of the empirical study conducted - with the view to developing a proposed water sector plan/functional flow chart for water services delivery for the Dr KKDM.

\section{Major research findings and development of a water sector plan for Dr KKDM}

As mentioned, this study made use of a qualitative research design and the case study approach. Triangulation was utilised as part of the case-study method. The Likert scale statements and open-ended questions were formulated to address the specific concerns regarding potable water supply by and within the Dr KKDM's municipal area. The major research findings from the research questionnaire are subsequently presented below.

On a Likert-scale of 1 being strongly disagree and 5 being fully agree, the 35 respondents agreed by $50 \%$ that the district municipality possessed specialised expertise to manage potable water. The $50 \%$ of respondents that have disagreed/strongly disagreed or were unsure about the statement are however reason enough to interpret that there are doubts as to whether the municipality indeed has adequate specialised expertise to manage its potable water supply. This statement investigated whether staff involved in the management of potable water supply had the necessary skills and specialised expertise, in order to fulfil tasks effectively. Public officials should be able to analyse, interpret and execute public management functions successfully, in order to manage resources in an effective, efficient, equitable, economic and sustainable manner. The expectation of this statement was, therefore, met by receiving a favourable response. 
The statement whether a WSP was in place for the Dr KKDM was aimed at determining where a district municipality is not a WSA, such as Dr KKDM, whether it should develop a "water sector plan" (WSP). Only 47\% of the respondents agreed/fully agreed that a WSP was in place for the Dr KKDM. However, 53\% were either unsure about the state of affairs or disagreed/strongly disagreed with the statement. The total number of responses that were unsure - including those that disagreed/strongly disagreed with the statement - outweighs the total number of responses that had agreed or fully agreed with the statement. This indicated to a great extent that a WSP was lacking in the Dr KKDM. This statement, therefore, provides proof that a WSP was non-existent for Dr KKDM - in order to effectively coordinate the management of potable water supply within the southern region of the North West Province.

Respondents were asked to indicate whether a WSP was included in the IDP of Dr KKDM. Municipalities now have developmental functions, which include service delivery to communities and the promotion of socio-economic development. This involves partnerships with communities and stakeholders and is a strategic process; which requires a great deal of planning and consultation. The majority of the respondents (59\%) were unsure about the state of affairs regarding the statement. Forty one percent of the respondents strongly disagreed with the statement. The results of this statement provide proof that the respondents were largely unsure as to whether a WSP is included in the IDP of Dr KKDM. The 59\% of the respondents who were unsure was worrying. This percentage is very high; and if they had made a choice it could have swayed the results either way. However, the researchers could not ignore this important result, as it indicated that members were uninformed about important strategic and planning business instruments by the Dr KKDM in its municipal area.

The major research findings from the semi-structured interviews inter alia included that one of the researchers asked the respondents to comment on the relationship between local municipalities and the district office (intergovernmental relations and co-operative governance). With this particular question, the researcher wanted to ascertain whether there was adequate support from the district office in terms of the facilitation of potable water supply management. It should be noted that the district municipality is not a WSA, but has certain co-ordinating functions to fulfil, including the development, implementation and maintenance of a water sector plan. The results indicate that there was a general perception that the amount of support received from the district office was inadequate for the management and effective delivery of potable water supply services in the Dr KKDM's municipal area of responsibility. This indicates that intergovernmental relations and cooperation are not functioning at its optimal level within the Dr KKDM. These issues would have to be addressed at district level.

From the aforementioned major research findings, the authors concluded that a water sector plan (WSP) was lacking in the Dr KKDM and that it was important and necessary to develop such a plan or a functional flow chart. The researchers developed the proposed WSP for the Dr KKDM by utilising the existing knowledge and institutional memory, and by way of the research methodology and empirical findings, as described in the foregoing. The plan/functional flow chart was furthermore developed in order to address the primary and secondary objectives of this study by taking into account the theories of public planning, strategy development and integrated water resources management. Figure 2 below depicts the proposed WSP for the Dr KKDM. The plan contributes to an understanding of the management surrounding a basic service, such as potable water within a district municipality, Td11(1), July 2015, pp. 64-81. 
which is not a WSA, but still has to take charge of the overall high-level planning and effective co-ordination processes and responsibilities. The plan also maps the current water management processes and practices, and it provides relevant information for its successful implementation. The plan, furthermore, holds certain benefits for water services delivery in the Dr KKDM region if the district municipality would be compliant.

Figure 2: Water sector plan/functional flow chart for the Dr KKDM

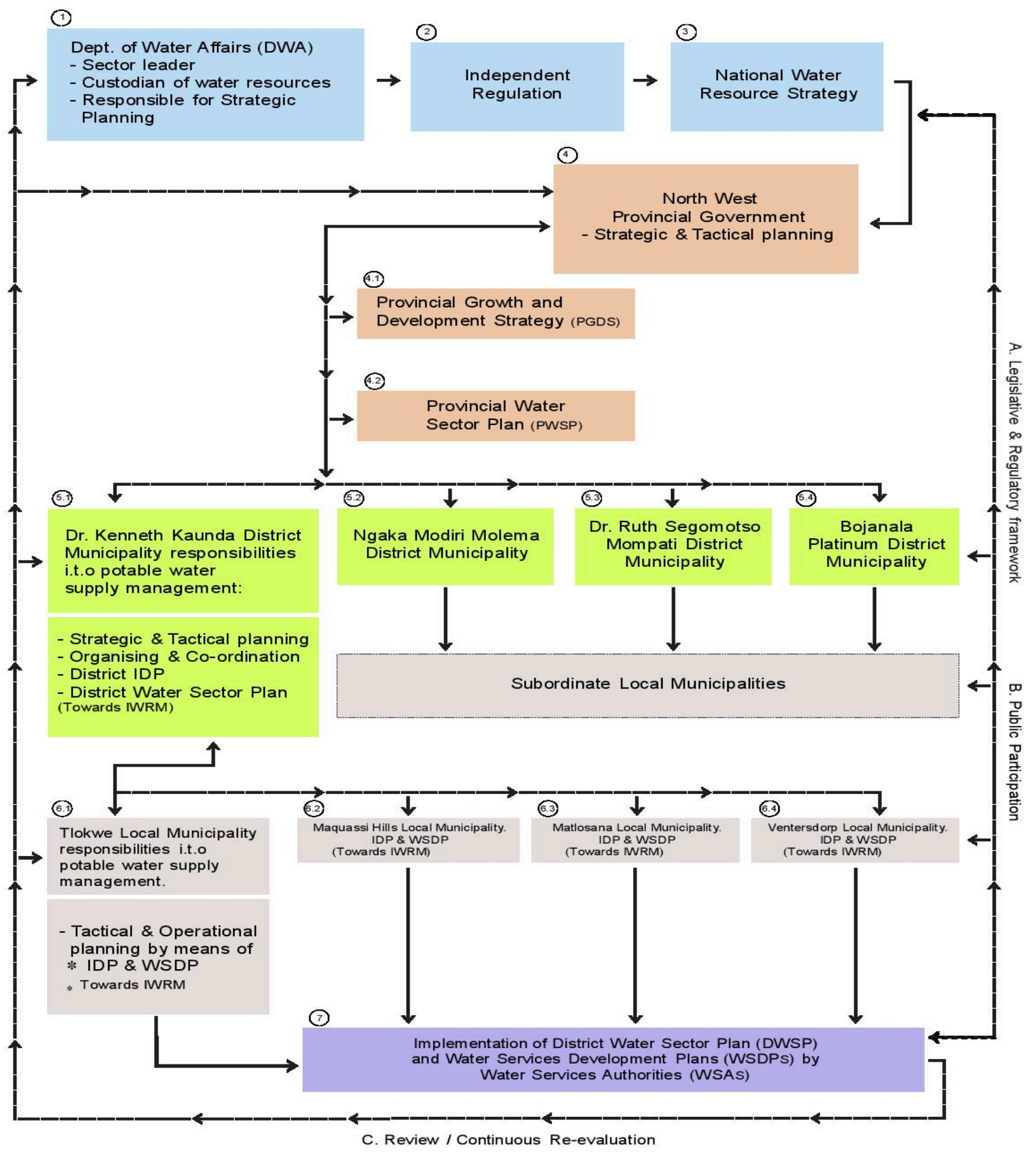

Source: Researchers' own drawing. 


\section{Discussion of elements of the proposed water sector plan}

In this section, the processes and elements of the proposed water sector plan are succinctly clarified and explained. The plan specifies the logical sequence and linkages between activities: in other words, mapping the process. A numbering system used in the proposed WSP has been retained for ease of reference purposes. Numbers 1-4 reflect the strategic level of the plan; 5 the tactical level and 6-7 the operational level.

The proposed WSP is, firstly, influenced to a significant extent by (A) the Legislative and Regulatory framework for water resource management in SA. The legislative and regulatory framework is an indication of the extent of intervention engaged by government, in order to regulate the governance of water resources. The main objective of a legislative and regulatory framework, as an element of the district water sector plan, is thus to strengthen, regulate and provide guidance in the water resource management sector of SA. Coupled with these legislative and regulatory requirements is the issue of public participation, discussed below as second element of the proposed DWSP for Dr KKDM.

The plan requires (B) public participation involving all the role-players and stakeholders. Public participation at local government sphere is a very important tool and an integral part of public developmental processes and decision-making. This implies that citizens should be involved in public decision-making, in order to ensure local democracy. According to Van der Waldt et al. (2014:27), public participation is the organised effort to increase control of resources (water as the example in this case) and regulative institutions by groups and movements, especially those excluded from such control. This particular element/variable in the proposed WSP alerts the local and district municipalities that it is of vital importance to have mechanisms and structures in place - to ensure adequate public participation in the management of potable water as a natural resource. This would provide ordinary citizens with the satisfaction of knowing that they are involved in the process, and are updated regularly regarding any problems that could arise. Communication is, consequently, a vital element in public participation processes. Different mediums of communication can be utilised to inform or invite citizens to participate in the affairs of the local authority (the WSA in this case). South African citizens should be involved in the management of integrated water resources by means of community participation in water catchment areas/regions. Forums such as the Mooiriver Catchment Forum can be joined in this regard. Furthermore, communities can also take part in for example the National Water Week programmes organised every year during March by DWA and local municipalities.

According to Lotz-Sisitka and Burt (2006:12), public participation has been identified as a key requirement for success in government programmes. Government projects are dependent on the willingness of the respective communities to assist in project implementation. Public participation has, therefore, been institutionally framed within government legislation relating to integrated water resources management (Lotz-Sisitka and Burt 2006:12). Public participation within government structures is, furthermore, made possible by "co-operative governance" (COG) and "intergovernmental relations" (IGR) (Mazibuko and Pegram 2006:4-11). COG seeks to ensure the management of a more sustainable environment meaning that there is a shift away from the narrow focus of governance to a broader focus. In a broader focus, a wider range of governance mechanisms is used regarding growing positions and roles of water associations and partnerships that reflect the dynamic and interactive nature of co-ordination and integration. This should facilitate a more accommodating environment for trans-disciplinary research and synergised outcomes which would entail the

Td 11(1), July 2015, pp. 64-81. 
incorporation of the collective and integrated synergies between the embedded environmental, economic viability (including technology), and social equity (including culture and politics) systems which are underpinned by or grounded in the facilitating system of governance and $\mathrm{COG}$ in a holistic quest towards effective public decision-making and policy implementation (Nealer and Diedericks, 2012:9). However, some challenges remain when it comes to stakeholder participation. The main objective of public participation as an element of the proposed WSP is thus to involve all the role-players and stakeholders in the governance processes and management of integrated water resources. Stakeholders and roleplayers' needs for potable water vary widely; therefore, they cannot be engaged and informed in a uniform way.

The proposed WSP is spearheaded at national government sphere by: (1) The Department of Water Affairs (DWA). In this regard, Thompson (2006:279) outlined that the National Government's role in managing, protecting and determining the use of scarce water resources is contained in the principle of "public trust" as discussed above. This responsibility is in accordance with the NWA 36 of 1998 and the NWRS of 2004 (chapter 1.2); and it includes ensuring that water is allocated equitably, and that environmental values are promoted. National Government is committed to carrying out its public trust obligations by being the custodian of the nation's water resources through the Department of Water Affairs (DWA). In this regard, the DWA is primarily responsible for the formulation and the implementation of government policy in this sector.

The DWA is, furthermore, responsible for strategic planning within the water services sector - by means of the drafting and implementing of the relevant policies. The DWA's specific functions in this regard include sector leadership, the promotion of good practice, the development and revision of national policies, the oversight of all legislation impacting on the water sector (including the setting of national norms and standards), co-ordination with other national departments on policy, legislation and other sector issues, national communications, and the development of national strategies to achieve water sector goals. The DWA also has the responsibility to develop policy with regard to international water service issues (DWAF 2003:20).

Amongst others, one of the important roles of DWA is: (2) The independent regulation of the water services sector by means of monitoring sector performance, including conformity with the national norms and standards, through mechanisms such as the Blue and Green Drop assessments, its water catchment regions, and making regulatory interventions to improve performance and/or to ensure compliance (DWAF 2003:20).

Considering elements 1 and 2 above of the proposed WSP, it can be unequivocally stated that the DWA is the leading functionary in the process representing national government, by being responsible for both the management of water resources and the provision of water services. The department is thus responsible for national strategic planning and oversight.

The aforementioned thus implies that some sort of a strategy must be put in place. In this regard, (3) the National Water Resource Strategy of 2004 (NWRS) is an important element/variable/activity of the proposed WSP, in the sense that it introduced a strategy on how the water resources of SA should be protected, used, developed, conserved, managed and controlled, in accordance with the requirements of the National Water Policy (NWP) and the National Water Act, 1998. The NWRS thus provides a blueprint for the management of water resources for the first time in SA. The control over the use of water has, however, changed by promulgation of the NWRS. According to the NWRS, a single organisation or 
institution cannot exercise complete authority over water. The responsibility for managing water resources has, therefore, been decentralised to include surface water catchment management agencies (CMAs) and the Water Tribunal.

At provincial government sphere, the North West Province has, for example, certain responsibilities in the facilitation of a potable water supply. In general, the responsibilities of (4) Provincial Governments in terms of potable water supply management include the constitutional responsibility to support and strengthen the capacity of local government in the fulfilment of its functions, and to regulate local government to ensure the effective performance of its duties.

Provincial public works departments may undertake (or oversee) the construction of water and sanitation infrastructure on behalf of other departments in the province. Typically, this would include setting design standards for water and sanitation facilities in schools, hospitals and clinics. Nevertheless, client departments remain ultimately responsible for the water supply and sanitation services within their own facilities, including the associated costs of bulk water and sanitation infrastructure, where appropriate (DWAF 2003:21).

The primary roles of the province regarding water services, furthermore, are the following:

- Monitor legislation through the National Council of Provinces.

- Ensure compliance with national policy and norms and standards.

- Develop enabling provincial legislation and norms and standards.

- Co-ordinate regional planning.

- Promote integrated development and inter-departmental co-ordination.

- Monitor progress (RSA 2001:21-22).

The medium-term planning of government in SA is informed by the Medium-Term Strategic Framework (MTSF). The MTSF guides planning and resource allocation across all spheres of government. In this regard, national and provincial departments in particular, need to develop their five-year strategic plans and budget requirements, taking into account the medium-term imperatives. Provinces should reflect the MTSF in their (4.1) Provincial Growth and Development Strategy (PGDS).

This is a collaborative framework to drive long-term development and implementation within the province as a whole (RSA 2005:2). The PGDS consists of two parts: a long-term strategic view (10-20 years) of the province, and an action-oriented collaboration and implementation plan (RSA 2005:6). The implementation plan should be reviewed annually with a focus on "driving" key strategies for effective implementation.

The implementation plan should also include a monitoring and evaluation framework, meaning a performance management system (RSA 2005:6) that measures whether the developmental goals identified in the PGDS were achieved against the desired outcomes. The PGDS is, furthermore, enhanced and promoted by making use of co-operative governance and intergovernmental relations structures, such as inter alia the MinMec's and Provincial Intergovernmental Forums.

Flowing from the PGDS is the development and implementation of (4.2) a provincial water sector plan. The purpose of the provincial water sector planning is an integral part of ensuring that provinces (which do not have water competence) and municipalities have the opportunity to participate in the development of national plans and strategies, and in 
particular, making decisions regarding water development and management regarding their areas of jurisdiction (NWP 2006:7). This is in accordance with the following considerations:

- National government, as discussed above, provides a framework for common policies, principles and priorities within which area (provincial and local) and sectoral planning can take place.

- The PGDS provides a more specific framework for the development of projects and programmes at a provincial programme level, as well as ensuring co-ordinated area and sectoral planning (RSA 2005:2).

- Municipalities should develop area-based IDPs to guide and inform all planning, implementation and management of service delivery in their areas. These plans must be compatible with national policy and legislation and be aligned with provincial strategies and plans. The area-based IDP of a municipality should specifically be linked to Water Services Development Plans (WSDP). The WSDP is a planning instrument within the water services sector, and its purpose is to assist water services authorities to carry out their mandate effectively by taking into account the socioeconomic, technical, financial, institutional and environmental issues pertaining to water services (Mazibuko \& Pegram, 2006:26). Plans should be regularly updated and progress should be reported on an annual basis, in order to assess how well water services authorities are performing relative to their stated intentions and their capacity (SA, 1997). This information would assist local communities and the DWA to determine the access to basic potable water services.

Each sphere's planning process takes into consideration the realities of other spheres and there is thus a mutual influence - not necessarily top-down or bottom-up only.

The purpose of provincial water sector planning, as an element of the proposed WSP is thus to take note of the following:

Nationally

- National water sector policies, legislation and strategies for both water resources and water services.

- National policies and strategies related to local government.

- Provincially

- Provincial growth and development strategies.

- Provincial local government support plans and strategies.

- Locally

○ Integrated Development Plans, including Water Services Development Plans (NWP 2006:7-8).

At the third sphere of the South African government are: (5) District and local municipalities - where basic services are rendered, such as the provision of potable water supply. According to the proposed WSP, it is important to determine whether the district municipality is a WSA or not. This is determined by the different categories of municipalities in SA. Dr $\mathrm{KKDM}$ is a category $\mathrm{C} 1$ municipality (5.1), a non-water services authority. According to the Water Services Act 108 of 1997, Thompson (2006:714), and verbal communication by means of a telephonic interview with Marais (2011), and e-mail communication by Ramaleba (2012), where a district municipality is not a WSA, such as Dr KKDM, it should develop a "water sector plan" (WSP). Such a plan should address the district-wide issues arising from the local WSDPs, and it should be included in the district's IDP (DWAF 2003:42). Dr 
$\mathrm{KKDM}$ is thus a non-WSA, but is still responsible for the development of a water sector plan by means of high-level planning (strategic and tactical planning), including the organising and coordination of functions in the region (the responsibilities and duties of WSAs, according to the Local Government: Municipal Structures Act 117 of 1998). Planning is thus instrumental for the effective management of potable water supply as a basic service.

The organising and coordination of the processes to provide sustainable potable water supply services are important functions of the municipal district office. In this regard, Riemann et al. (2012:445) refer to organising (implementation) as making optimum use of the resources required for enabling the plans to be carried out successfully. Coordination and control refer to evaluating progress against plans, which may need modification, based on feedback (Riemann et al. 2012:445).

The co-ordination of potable water is concerned with aspects that ensure that planning implementation conforms to the planning requirements, and that proper inter-relationships are met or established. Once the district municipal office has fulfilled its planning role, it should ensure that the plans are implemented according to the requirements, and that there are good relations among all the stakeholders involved for the effective service delivery of water as a basic service. Planning and coordination are cyclical and continuous processes. They should have clear timeframes set for the achievement of objectives and relevant activities. The planning process within municipalities is based on the development of an integrated development plan (IDP). Planning around water-related issues should consequently be highly prioritised by district municipalities, although they may not be WSAs, such as Dr KKDM. It is, therefore, important to include all water-related planning in the municipality's IDP, as required by the Water Services Act 108 of 1997, in order to prepare the municipal region for the necessary strategic growth and development. After the inclusion of all relevant water-related planning into the district municipality's IDP, it is necessary to draft a district water sector plan. Such a plan should provide proof that all district-wide water-related issues, as addressed in the WSDPs of the WSAs and the IDP of the district municipality, are addressed. Such a plan should at least address issues on a strategic, tactical and operational level. This implies the following consequences for the proposed WSP:

- The strategic planning of the water sector plan refers to the macro-planning for the region (entire Dr KKDM's municipal area), and should typically, include a holistic overview of the most important issues pertaining to effective potable water supply management.

- Tactical water-related planning refers to the short- or medium-term strategies of the municipal area, where it would be vital to outline how the objectives would be achieved.

- Operational planning refers to the day-to-day processes of managing potable water supply, where the focus would be on the quality and quantity of water to satisfy customer needs, and to bring about effective municipal service delivery.

The above elements, as described, are to a significant extent influenced by operational planning directed by the local category B municipalities. Local municipalities (6) are the most important elements/units in the proposed water sector plan because they render basic services to communities at large. There are four category B municipalities in the Dr KKDM region. All four local municipalities are WSAs. It is important that the four WSAs fulfil their mandate, namely: the provision of quality potable water and excessive quantities of water. 
This is achieved by means of drawing up Water Services Development Plans (WSDPs), according to the requirements of the DWA and the relevant municipal regulations. All four of the local municipalities (WSAs) in this study have a WSDP in place, although these have not been annually updated since 2010 by some. The annual review, implementation and maintenance or updating of the WSDPs proved, however, to be cumbersome, and required capable and knowledgeable people to manage the processes. In this regard, the district office (Dr KKDM) would have to play a much bigger role in getting its subservient municipalities capacitated to compile WSDPs - and subsequently updating them every year.

Once the proposed WSP and WSDPs have gone through the stages, as discussed above, it is necessary to (7) implement them effectively. Implementation refers to the carrying out, the execution, or practice of a plan, a method, or any design for doing something. It is thus the action that must follow any preliminary thinking, in order for something to actually happen. The implementation process is dependent on a number of factors, such as having an appropriate infrastructure and relevant resources available.

Furthermore, for the implementation process to transpire without any stumbling blocks, accountable and responsible officials and stakeholders should be running the operational processes; and, where necessary, appropriate training should be provided, in order to bring about the necessary competence for the process to flourish. The implementation process, however, can only be successful if it is properly evaluated to determine whether the necessary standards and criteria of the plan were met. This will be discussed next.

Assessment of the effective functioning of the proposed WSP for Dr KKDM is one of the most important elements/activities. This would transpire by $(\mathrm{C})$ reviewing the process by means of continuous re-evaluation. Assessment is the process of gathering, analysing, interpreting and using information about the plans' progress and achievement to improve the quantity and quality of water as a basic service by Dr KKDM in its municipal area. Assessment of the plan in this regard would entail monitoring and measuring the progress.

The success of the plan should be reported to the relevant programme administrators, public policy makers and government officials. Reporting goes hand-in-hand with the idea of being formally held accountable and responsible in government, according to good governance requirements and characteristics. Reporting in terms of water management, furthermore, indicates that all the stakeholders are responsible for ensuring the quality of drinking water to inhabitants within municipal boundaries, and also for ensuring that adequate quantities are available for the growth and development of the region. This would provide an indication of whether the organisational and specific planning requirements have been met.

After having gone through the processes of monitoring, measuring and reporting on the success of the plan, it is important to evaluate the plan in its current format. Evaluation, therefore, measures how well the plan activities have met the expected objectives, and/or the extent to which changes in outcomes could be attributed to the water sector plan. Evaluation would help in making informed decisions regarding service delivery, the daily operations and activities of the plan, which are based on objective evidence learned from experience.

Evaluation, however, should happen throughout the life of the water sector plan, and it should not just be applied towards the end. The last step in the assessment process would be to make the necessary changes or improvements (modification), in order for the plan to function more effective and efficiently. The changes would significantly impact on the planning and coordination efforts of the district municipality in the supply of potable water in 
the future. Monitoring/measuring, reporting, evaluation and modification are important indicators of whether potable water supply is being managed effectively within municipal areas, according to the government requirements and regulations.

\section{Conclusion and recommendations}

This research aimed to develop a proposed water sector plan/functional flow chart for the $\mathrm{Dr}$ KKDM, taking into account municipal and water management aspects, such as the effective potable water supply, data monitoring and capturing, as well as the incorporation of a more holistic and integrated water resource management approach (IWRM), according to the DWA's envisaged demarcated surface water catchment regions. Application of the proposed water sector plan by municipalities situated within the Dr KKDM area of jurisdiction by means of improved co-operative governance and intergovernmental relations could, therefore, contribute to more effective, efficient and economical service delivery in terms of the integrated management of water resources.

The following recommendations for future research are made, based on the literature review and empirical findings of this study in order to improve water-related planning and management within South African government spheres:

- The role and functions of district municipalities that are not WSAs need further investigation. The role of such municipalities is currently outlined in the Strategic Framework for Water Services of 2003 (DWAF 2003:42), as only being responsible for the development of water sector plans. However, these plans are lacking throughout the sector.

- The role and functions of provincial governments in the management of water resources need clearer description, especially the link between the PGDS, the Provincial Water Sector Planning and District IDPs. The issue of co-operative governance and intergovernmental relations between districts and provinces in terms of water-related planning and management thus needs to be researched.

- Water-related challenges within local municipalities are worrying, such as the outdated infrastructure, the shortage of skilled personnel and the lack of succession planning to retain skills; failure by means of adhering to monitoring mechanisms, such as the Blue and Green Drop status. The lack of skills currently seems to be the major constraint in facilitating effective service delivery by municipalities.

\section{References}

Babbie, E. and Mouton, J. 2002. The practice of Social Research. Cape Town: Oxford University Press Southern Africa Ltd.

Department of Water Affairs and Forrestry (DWAF). 2003. Strategic Framework for Water Services. Pretoria: DWAF.

Demarcation Board. 2011. Maps of Maquassi Hills Local Municipality, Dr Kenneth Kaunda District Municipality, Matlosana Local Municipality, Tlokwe local Municipality Eo Ventersdorp Local Municipality. Available at

(http://www.demarcation.org.za/Downloads/BoundaryData/NorthWest, 2011). Accessed 03 August 2011. 
Fuggle, R. F. and Rabie, M. A. 2005. Environmental management in South Africa. Landsdowne: Juta \& Co Ltd.

Funke, N., Nortje, K., Findlater, K., Burns, M., Turton, A., Weaver, A. and Hatting, H. 2007. Redressing Inequality: South Africa's New Water Policy. Environment Science and Policy for sustainable Development, 49(3), 21 April.

Lotz-Sisitka, H. and Burt, J. 2006. A critical review of participatory practice in integrated water resource management. Grahamstown: Water Research Commission. WRC Report No: 1434/1/06.

Marais, S. 2011. Telephonic interview with the author (Director, DWAF: Water Services Planning and Implementation of strategies, Pretoria offices). Potchefstroom. 08 July.

Maree, K. (ed), Creswell, J.W., Ebersöhn, L., Eloff, I., Ferreira, R., Ivankova, N.V., Jansen, J.D., Nieuwenhuis, J., Pietersen, J., Plano Clark, V.L. and Van der Westhuizen, C. 2012. First steps in research: revised edition. Pretoria: Van Schaik Publishers.

Mazibuko, G. and Pegram, G. 2006. Evaluation of the opportunities for cooperative governance between catchment management agencies and local government. Water Research Commission. WRC Report No: 1433/1/06.

Nealer, E.J. and Raga, K. 2008. Knowledge about the origin of a municipality's potable water: a prerequisite for consolidation of more effective local governance. Journal of Public Administration, 43(3.1):294-307, October.

Nealer, E.J. and Diedericks, M. 2012. Public Management and Governance's approach to transdisciplinary research in the Far West Rand area. Paper presented at the $3^{\text {rd }}$ Ecohealth Forum. Vanderbijlpark: Southern Sun Hotel.

North West Province (NWP). 2006. Provincial Water Sector Plan 2007/8 - 2011/12. Mahikeng. North West Water Sector Forum.

Riemann, K., Chimboza, N. and Fubesi, M. 2012. A proposed groundwater management framework for municipalities in South Africa. Water $S A, 38(3): 445-452$.

Ramaleba, M. 2012. Water Services Development Plan and Water Sector Plan Enquiry. E-mail communication: 25 July 2012. [Deputy Director: Water Services Planning, DWA, Pretoria Head Offices].

Republic of South Africa (RSA). 1994. White Paper on Water Supply and Sanitation Policy. Pretoria: Government Printer.

Republic of South Africa (RSA). 1996. Constitution of the Republic of South Africa Act, 1996. Pretoria: Government Printer.

Republic of South Africa (RSA). 1997. Water Services Act 108 of 1997.Pretoria: Government Printer.

Republic of South Africa (RSA). 1998a. Local Government: Municipal Demarcation Act 27 of 1998. Pretoria: Government Printer.

Republic of South Africa (RSA). 1998b. National Water Act 36 of 1998. Pretoria: Government Printer.

Republic of South Africa (RSA). 1998c. Local Government: Municipal Structures Act 117 of 1998. Pretoria: Government Printer. 
Republic of South Africa (RSA). 2000. Local Government: Municipal Systems Act 32 of 2000. Pretoria: Government Printer.

Republic of South Africa (RSA). 2001. Regulations relating to compulsory national standards and measures to conserve water. Pretoria: Government Gazette 22355 of 8 June 2001.

Republic of South Africa (RSA). 2005. Provincial Growth and Development Strategy Guidelines. Pretoria: The Presidency.

Thompson, H. 2006. Water law: a practical approach to resource management Eo the provision of services. Cape Town: Juta\& Co Ltd.

Van der Waldt, G. (ed), Venter, A., Van der Walt, C., Phutiagae, K., Khalo, T., Van Niekerk, D. and Nealer, E. 2014. Municipal Management: Serving the People. $2^{\text {nd }}$ ed. Cape Town: Juta \& Company Ltd.

Welman, C., Kruger, F. and Mitchell, B. 2011. Research methodology. (3 ${ }^{\text {rd }}$ ed). Cape Town: Oxford University Press Southern Africa Ltd. 